\title{
Review of the Lessons from the Mental Health Care in a Public Health Context Short Course: Australia Awards Africa
}

\author{
Brian Maila ${ }^{1,2 *}$, Denis Mbako Jato ${ }^{3}$
}

${ }^{1}$ Chainama Hills College Hospital, P.O. Box 30043, Lusaka, ZAMBIA

${ }^{2}$ The University of Zambia, School of Medicine, Department of Psychiatry, P.O. Box 50110, Lusaka, ZAMBIA

${ }^{3}$ Integrated Health for All Foundation (IHAF), P. O. Box 31717, Biyem-Assi, Yaounde, CAMEROON

*Corresponding Author: brianmaila34@gmail.com

Citation: Maila, B. and Jato, D. M. (2021). Review of the Lessons from the Mental Health Care in a Public Health Context Short Course: Australia Awards Africa. European Journal of Environment and Public Health, 5(2), em0068. https://doi.org/10.21601/ejeph/9369

\section{ARTICLE INFO}

Received: 15 Aug. 2020

Accepted: 11 Oct. 2020

\begin{abstract}
The World Health Organisation (WHO) recommends human resource development as a key strategy to promote global mental health. The optimal approach to building capacity in global mental health care requires partnerships between professional resources in high-income countries and promising health-related institutions in low- and middle-income countries. In this paper, we briefly describe the objectives of one of such initiatives, the Australia Awards Short Course titled, 'Mental Health Care in a Public Health Context', sponsored by the Australian Government, share our experience and reflections as participants in the program, and highlight key lessons relevant for scale-up of mental health care in low-middle income countries in Africa.
\end{abstract}

Keywords: Australia Awards Africa, mental health care, public health, capacity building, global mental health, task-shifting, stigma, gender, trauma, policy, financing

\section{INTRODUCTION}

Human resources are the most valuable asset of a mental health care system. The competence and motivation of mental health workers is critical in the promotion of mental health, prevention and provision of care for people with mental disorders (WHO, 2005a). Yet the median number of mental health workers in low-income countries are as low as below 2 per 100,000 population compared to over 70 per 100,000 in high-income countries (WHO, 2017). For instance, Africa has 1.4 mental health workers per 100000 people, compared with a global average of 9.0 per 100000 , and also performs relatively poorly with regard to the number of psychiatrists, the number of hospital beds for patients with mental illness, and the coverage of outpatient facilities (Sankoh et al., 2018). As a consequence, the proportion of Africans who receive treatment for mental health problems is extremely low. While the global annual rate of visits to mental health outpatient facilities is 1051 per 100000 population, in Africa the rate is 14 per 100000 (Sankoh et al., 2018). In view of this gap, there is need for governments, researchers, and journals to increase attention to mental health in order to increase service coverage for mental health disorders. Developing human resources is one of the key strategies recommended by the World Health Organisation to address global mental health problems in the World Health Report released in 2001 (WHO,
2001). A study titled, 'Capacity Building in Global Mental Health: Professional Training' suggested that the optimal approach to building capacity in global mental health will require partnerships between professional resources in highincome countries and promising health-related institutions in low-middle income countries (Fricchione et al., 2012).

The Australia Awards Africa short course titled, 'Mental Health Care in a Public Health Context' funded by the Australian Department of Foreign Affairs and Trade provides an excellent example of a partnership between a High Income country, Australia and nine low-middle income countries in Africa (QUT, 2019) to address mental health in low resource settings. The course, administered by the Queensland University of Technology (QUT) was undertaken at QUT in Brisbane, Australia, and Stellenbosch University, in collaboration with the Alan J. Flisher Centre for Public Mental Health, for the South African component. The program sought to introduce participants from Botswana, Cameroon, Ghana, Madagascar, Nigeria, Tanzania, Uganda, Zambia, and Zimbabwe to good practice in tailoring mental health practice to fit the cultural context and address prevention, early detection, early intervention, clinical skills and leadership, underpinned by the principles of gender equality and social inclusion (QUT, 2019).

In this paper, we share our experiences on mental health in Australia and South Africa drawing upon visits to innovative service providers and a museum documenting the impact of 
colonisation in Africa, and also outline some of the key lessons learned from seminars and lectures by experts in global health. Lessons learned are encapsulated in a number of recommendations resulting from our experiences.

\section{REFLECTIVE ACTIVITIES}

Apart from seminars, an important aspect of the Short Course involved site visits to organisations working in mental health in Brisbane, Australia and Cape Town, South Africa.

\section{Brisbane, Australia}

This section highlights the various site visits to organisations in Brisbane working to address the needs of people with a history of severe mental illness, the needs of people from refugee backgrounds and those with alcohol and drug dependency problems within the community.

\section{Addressing the Needs of People with a History of Severe Mental Illness}

People with a history of severe Mental illness require accesses to housing, employment, friendship and families. This section highlights the role of stepping stones in meeting such demands for patients with mental illness in Brisbane.

\section{Stepping Stones}

Stepping Stones is a Non-Governmental Organisation (NGO) comprising a community of people with mental illness, using an innovative strength-based approach to tackle mental illness by building their skills notwithstanding their illness, diagnosis, disabilities and deficits. This philosophy, drawing upon a recovery model, acknowledges fairness in delivering high quality of life for mentally ill persons. Stepping Stones Club House members are given opportunities to re-join the world of friendship, family, education, employment, safe and affordable housing, social recreation, and access to the services and supports tailored to their individual needs. The Club House model contributes to reduce number of hospitalisations, increased employment, and education levels, provision of structure and purpose, reduction in the risk of homelessness, development of a support system and collaboration with existing services. The recoveryrehabilitation centres as part of a human rights movement, seek to elevate people with a history of mental illness to employees, neighbours, members, leaders, friends, voters, peers and colleagues, thereby reducing social isolation, stigma and discrimination (Staples and Stein, 2008).

Low-middle resource settings with political will to decentralise mental health services could therefore learn from the clubhouse model of care and use lessons from such community-based facilities to valorise the skills in individuals.

\section{Addressing the Needs of People from Refugee \\ Backgrounds who have experienced Trauma}

Individuals from refugee backgrounds experience traumatic experiences and various mental health consequences associated with trauma and torture. In this section, we highlight the role of Queensland Programme of Assistance to Survivors of Torture and Trauma in Brisbane.
Table 1. Impact of Trauma and the goals of treatment

\begin{tabular}{|c|c|c|}
\hline $\mathrm{S} / \mathbf{N}$ & $\begin{array}{l}\text { Core components of the } \\
\text { Trauma Reaction }\end{array}$ & The Recovery Goals \\
\hline 1. & $\begin{array}{l}\text { - Anxiety } \\
\text { - Feeling of helplessness } \\
\text { - Perceived loss of control }\end{array}$ & $\begin{array}{l}\text { To restore safety, enhance } \\
\text { control and reduce the } \\
\text { disabling effects of fear and } \\
\text { anxiety }\end{array}$ \\
\hline 2. & $\begin{array}{l}\text { - Relationships changed } \\
\text { - Capacity for intimacy altered } \\
\text { - Grief } \\
\text { - Depression }\end{array}$ & $\begin{array}{l}\text { To restore attachment and } \\
\text { connections to other human } \\
\text { beings who can offer } \\
\text { emotional support and care }\end{array}$ \\
\hline 3. & $\begin{array}{l}\text { Shattering of previously held } \\
\text { assumptions: } \\
\text { - loss of trust } \\
\text { - meaning and identity destroyed } \\
\text { - view of the future altered }\end{array}$ & $\begin{array}{l}\text { To restore meaning and } \\
\text { purpose to life. }\end{array}$ \\
\hline 4. & $\begin{array}{l}\text { - Guilt } \\
\text { - Shame }\end{array}$ & $\begin{array}{l}\text { To restore dignity and value } \\
\text { which includes reducing } \\
\text { excessive shame and guilt }\end{array}$ \\
\hline
\end{tabular}

\section{Queensland Programme of Assistance to Survivors of} Torture and Trauma (QPASTT)

Australia receives up to 20,000 people a year from refugee backgrounds, many of whom have been exposed to trauma and its consequences. QPASTT provides a range of flexible and culturally sensitive community-based services to people who have been tortured, or suffered refugee-related trauma, prior to migrating to Australia. It is based in Queensland but is part of a national organisation dedicated to the wellbeing of people from refugee backgrounds. It is an example of government's involvement in addressing physical, psychological and social challenges that survivors of torture and trauma experience. Addressing the consequences of trauma also contributes to people's capacity to deal with migration and contribute to the community over time.

While, in parts of Africa, we may not be directly involved in the care of individuals from a refugee background as mental health professionals, the lessons from QPASTT on the goals of recovery for survivors of torture and trauma is still applicable to all forms of trauma (gender-based violence, child abuse, sexual abuse and potentially, loss through COVID-19), encountered in our routine practice. Table 1 illustrates the effects of trauma and the corresponding goal of treatment adopted from QPASTT and The Victorian Foundation for Survivors of Torture (QPASTT, 2014; VFST, 2016).

Many victims of torture and trauma in Africa still bear scars of slavery and rampant civil wars. Over the last 40 years, nearly 20 African countries have experienced at least one civil war leading to the death and displacement of many millions of people (2.3 million and 720,000 in South Sudan and Democratic Republic of Congo respectively displaced to neighbouring countries, further compounding efforts to restore dignity and hope.

\section{Addressing the Needs of People with Alcohol and Drug Dependency Problems}

This section describes a site visit to Biala City Community Health Centre, which addresses the needs of people with Alcohol and drug dependency problems within the community. 


\section{Biala City Community Health Centre}

Biala City Community Health Centre provides high quality outpatient detox, inpatient detox and counseling, Needle and Syringes Programs (NSP), Opioid Replacement Therapy (ORT), and group therapy programs to individuals, families, and communities affected by alcohol and other drugs. The main approach is harm reduction and is usually patient-centered with the patient generating their own goals for treatment.

The visit to Biala City Community Health Centre exposed us to the knowledge about ORT with the ultimate result of implementing such an intervention in a small pilot study in Zambia upon completion of the Australian component of the program. At 15 weeks of ORT, the patient showed positive outcomes and he became an advocate for the program. This is indicative of how successful such a program can be when tailored to the African context, though efforts need to be made to diminish risk factors of Substance Use Disorders (SUDs) to avoid relapse.

\section{Cape Town, South Africa}

The second component of the program involved learning seminars and visits to programs in Cape Town, South Africa. In this section, we highlight the site visits to the Slave Lodge in Cape Town, with a focus on colonialism and mental health. We further highlight the role of the trauma centre for Survivors of Violence and Torture in addressing the psychosocial impact of trauma and torture, and the Innovations in Institutional Care of People with Mental Illness at Lentegeur Hospital (LGH) and Alexandra Hospital.

\section{Colonialism and Mental Health}

A visit to the Slave Lodge in Western Cape, Cape Town, South Africa addressed awareness of colonialism in Africa and its impact on mental well-being in the present and implications for the future. Displayed images, writings, and videos clearly illustrated how slavery and slave trade have left unforgettable memories in the minds of victims, with ripple effects across generations. A phrase at the reception of the Slave lodge, "Slavery is no longer legal yet it continues to exist in different forms" further confirms continuation of slavery in other forms (debt bondage, human trafficking, sexual exploitation and child labour), with enormous emotional and psychological impacts. It is therefore imperative that political will be exercised through intentional appeasement measures (compensation to victims and freedom from economic and political slavery in Africa) to address such feelings in the present generation, and avoid a continuous spillover to future generations resulting from growing bitterness.

\section{Addressing the Psychosocial Impacts of Violence and Trauma}

This section describes the role of the trauma centre in alleviating the psychosocial effects of violence and trauma for survivors of violence and torture in Cape Town.

\section{Trauma Centre for Survivors of Violence and Torture,} Scalabrini Centre

This NGO, established in Cape Town nearly 20 years ago, supports South Africa in becoming a violent-free society with respect for human rights. The centre played an important role in healing South Africa's wounds of apartheid, national rebirth, reconstruction and recovery (Directory of Services and Resources for Survivors of Torture, 2003). It hosted Nelson Mandela and many other political prisoners after their release and has since 1994, continued to provide psychosocial assistance to people affected by trauma during the apartheid era. More survivors of the post-apartheid era, mostly women and children (Directory of Services and Resources for Survivors of Torture, 2003) have been seeking the services of the centre. The centre also links survivors of trauma and torture to other services and collaborates with the United Nations High Commissioner for Refugees (UNHCR) to help refugees who feel threatened in South Africa and wish to be relocated to other countries of safety. With growing political crises in many African countries, it is important for mental health practitioners and policy makers to emulate centres like Scalabrini and provide psychosocial services to survivors of trauma within their own context.

\section{Innovations in Institutional Care of People with Mental Illness}

This section highlights the innovations in institutional care of people with mental illness, with a focus on Lentegeur and Alexandra Hospitals of the Western Cape Province of Cape Town.

\section{Lentegeur Hospital (LGH) and Alexandra Hospital}

Presentations of projects, challenges and responses in service delivery at these facilities provided an understanding of mental health service, development and leadership in the public sector. In addition to lectures, sessions at Lentegeur and Alexandra Hospitals included interviews of people with lived experiences of mental illness. After listening to how they successfully fought their way through, the take-home message could be summarized in the phrase, "No health without mental health". This calls for improved mental health infrastructure, human resource and financing across Africa.

Lentegeur Hospital (LGH) and Alexandra Hospitals are examples of some of the large capacity mental hospitals offering both in and outpatient services in the Western Cape Province of Cape Town. Spring Foundation, an NGO based at the LGH supports psychosocial rehabilitation through an innovative approach by fully embracing the recovery concept, skills building and reintegration options. This approach helps to re-establish a sense of hope and recovery through reconnection to community, and has changed the way in which Mental Health services are perceived, offered and utilised. Also, its training agreements with multiple higher education institutions, notably the Universities of Cape Town and Stellenbosch offer opportunities for research and capacity building.

Alexandra Hospital is a specialised mental health facility providing services for mental health and intellectual disability. Its deinstitutionalisation of services has led to a decline in inpatients, thereby improving health outcomes. Collaboration between Lentegeur and Alexandra Hospitals to provide services to children, adolescents, and adults, with focus on behaviour management and developmental skills training is a complementary and inclusive approach worth emulating. 
Although the experiences of Australia and South Africa are quite innovative and worth emulating, their success stories have not been without challenges in human resources, financing, diagnosis, policy, and culture. For example, the Spring Foundation may not be adopted on a copy and paste basis but must be adapted to fit into country context.

\section{KEY LESSONS LEARNED}

This Section describes the lessons learnt from the short course seminars and lectures in both Brisbane and South Africa for mental health care in Africa. The areas covered include, planning mental health programs with stakeholders, taskshifting, mental health and chronic illness, mental health and stigma, psychological tools in context, mental health and gender, mental health policy, research in mental health and mental health financing.

\section{Planning Mental Health Programs with Key Stakeholders}

During the lectures, the need to involve key stakeholders in developing mental health programs was prioritised. Community engagement, for example, is a powerful vehicle to bring about environmental and behavioural change that have capacity to improve the health of the community and its members (Susskind, 2013). Relationships like these serve as catalysts to change policies, programs and practices (Susskind, 2013). A study titled, 'Developing a mental health care plan in a low resource setting: the theory of change approach' undertook an iterative Theory of Change development process involving multiple workshops with stakeholders from diverse backgrounds. Participation in this process was engaging, encouraged strong commitment among participants and was an effective approach to developing a pragmatic and community based mental health care plan (Hailemariam et al., 2015). The involvement of multiple stakeholders at different levels illustrates a pathway to elicit stakeholder buy in, help planners to define assumptions from the start of the process, and reduce uncertainties about the implementation (Hailemariam et al., 2015). This approach may serve as an important framework in identifying the necessary and sufficient conditions for promoting intended long-term outcomes of the program to reality for participants (Hailemariam et al., 2015).

\section{Task-shifting as an Innovative Strategy for Scaling up Global Mental Health}

In low-middle income countries where human resources for mental health care is extremely limited, task-shifting was introduced as an effective methodology for mental health workers to increase capacity of mental health care systems. Global mental health advocates generally agree that the introduction of large number of psychiatrists and psychologists in low-middle income countries are currently unaffordable and unlikely (Freeman, 2016). Within a global mental health framework, alternatives would be integration of mental health within general health care and a task-shifting or task-sharing approach, backed by research and logical arguments (Freeman, 2016). An example of this practice is seen in Cameroon with integrated mental health services under specialist supervision of visiting psychiatrists due to acute shortage.

Task-sharing may improve access and effectiveness of mental health care in rural and other low-resource settings (Hoeft et al., 2018). A study by Joshi et al. (2014), on taskshifting for management of non-communicable diseases (NCDs), improved health outcomes (reductions in blood pressure, increased medication uptake and lower depression scores) when compared with usual healthcare. Task-shifting from physicians to non-physician healthcare workers (NPHWs), if accompanied by health system re-structuring and capacity building is a potentially effective and affordable strategy for improving access to healthcare for NCDs (Joshi et al., 2014).

Chibanda et al. (2011), in a pilot study of low-cost multicomponent 'Friendship Bench Intervention' for chronic mental disorders, trained lay workers for 8 days in screening and monitoring common mental disorders. Further training in problem-solving therapy was offered to adult attendees who either were referred or self-referred to the friendship bench. Findings included preliminary evidence of clinically meaningful improvement in common mental disorders associated with locally adapted problem-solving therapy delivered by lay health workers through routine primary health care in an African setting. A recommended randomised controlled trial to test the effectiveness of the task-shifting mental health intervention (Chibanda et al., 2011), of patients with common mental disorders found that the group which received the lay health worker-delivered psychological intervention had significantly lower symptom scores after 6 months compared with a control group which received enhanced usual care (Chibanda et al., 2016). The generation of contextually innovative strategies to implement a tasksharing approach to mental health care by mental health practitioners and policymakers in low-middle income countries is encouraged.

\section{Mental Health and Chronic illness}

In 1948, the World Health Organization (WHO) modernized the definition of health to include mental and social dimensions, leading to a modified definition of health as "a state of complete physical, mental, and social well-being, and not merely the absence of disease or infirmity" (health on the mind, 2018). This definition challenges the biomedical model which leaves little room for the social, psychological, and behavioural dimensions of illness (Engel, 1977). Limitations of this model include fixation on discovering pathology rather than understanding the illness, failure to explain functional somatic syndromes and illness without discernible disease, explanation of illness using single-factor models, (biological malfunction) and reduction of illness to micro-level processes, such as chemical imbalances (Engel, 1977; Wade and Halligan, 2004).

In contrast, a biopsychosocial model is an interdisciplinary model that looks at the interconnection between biology, psychology, and socio-environmental factors (Suls and Rothman, 2004). It specifically examines the role psychosocial aspects play, ranging from health and disease models to human development (Suls and Rothman, 2004). Developed by 
George L. Engel in 1977, it is the first of its kind to employ a multifaceted thinking (Pilgrim, 2015).

Despite being criticised for its limitations, the biopsychosocial model continues to influence the fields of psychology, health, medicine, and human development (Pilgrim, 2015). Gagliese et al. (2018) found that about half of people with dementia, whether in community or institutional settings, report pain, with depression as a significant burden. This study proposed that pain in older people with dementia is the result of an intricate network of interactions of three biopsychosocial phenomena: biological, psychological and social factors. Another study conducted in Australia demonstrated the importance of including psychological, biological and sociocultural factors in models of body image and eating concerns in young female adolescents (Rodgers et al., 2014). Mental health complications of medical conditions is an increasingly recognised issue with implications on the quality of life (Bolton and Gillett, 2019). Considering the interaction of psychological, biological, socio-cultural factors, there is need for diagnosis and management of illness in lowmiddle income countries in Africa to consider incorporating psychological services into physical healthcare pathways. We have seen some progress in this regard, with psychologists and psychiatry registrars working under mental health in the University Teaching Hospital of Zambia, and a health psychologist working in the Clinical Psychology Centre of the Greater Accra Regional Hospital in Ghana.

\section{Mental Health and Stigma}

Stigma may be defined as, "an attribute that is deeply discrediting" and reduces the stigmatized person "from a whole and usual person to a tainted discounted one" (Goffman, 1963: 3). Stigmatisation is one of the major barriers to seeking mental health care, both in Australia and in parts of Africa. This has been reported among the Arabic-speaking community in Australia, linked to the shame of disclosing personal and family issues to outsiders (Youssef and Deane, 2006). This has significantly contributed to under-reporting of mental health ailments, compared to other health conditions (Bharadwaj et al., 2017). The fear of being negatively labelled, is thought to cause treatment avoidance, increase dropout from treatment and reduce treatment adherence (Bährer-Kohler and CarodArtal, 2017). Stigma may reduce the well-being of persons experiencing mental illness (Soghoyan and Gasparyan, 2017), considering that the internalisation of negative views has been linked to low self-esteem, self-blame and negative emotional states (Clark et al., 2013). Stigma, discrimination and recurrence of symptoms, have deprived mentally ill people from securing adequate education and employment over their lifetime (Bährer-Kohler and Carod-Artal, 2017), leading to a drift into poverty, further compounding their mental health condition.

Key steps highlighted by California Mental Health Services Authority could be adapted to address mental healthassociated stigma in Africa. Firstly, by creating a supportive environment for consumers of mental health services and families. Secondly, promoting awareness, accountability and change. Thirdly, increasing knowledge of effective and promising programmes among the mental health care providers and lastly, upholding and advancing laws to eliminate discrimination (CalMHSA, 2010).

Considering the negative impacts of stigma on the mental health of affected individuals, the families and the economy of the country, there is need for low-middle income countries in Africa to generate local solutions to combat it so as to improve mental health-seeking behaviours.

\section{Psychological Tools in Context}

Mental health may be advanced by the development and adoption of instruments which encourages assessment of the prevalence and incidence of a range of mental health indices. Such knowledge inspire improved psychological research and clinical practice (Iliescu, 2017). Adapting tests to various cultural contexts is a critical process, requiring a combination of knowledge and skills from psychometrics, cross-cultural psychology, and others (Iliescu, 2017).

This process involves both translation and adaptation to address fidelity versus fit of a test to a particular cultural context (Castro et al., 2004; Iliescu, 2017). Test translation, though immensely important, is only a part of the more encompassing test adaptation process (Iliescu, 2017). Test translation is linguistically driven with the emphasis being content rather than intent, focusing on capturing the content of the original text than staying true to its intent (Iliescu, 2017). Test adaptation is a rigorous scientific process, most prominent being the need to offer proof for the appropriateness of said linguistic transformation, beyond language to psychometric characteristics. This process is validity-driven and emphasises intent rather than content (Iliescu, 2017). Therefore, staying true to the intent of the original text is more important than capturing the original content.

In view of the aforementioned, cultural adaptation requires involvement of multiple stakeholders. In the African context, it requires a research team comprised of researchers, practitioners, content experts and the community. A diversely represented advisory committee with ongoing engagements during the development phase and representatives from the context where the work will actually be done are also important stakeholders.

\section{Mental Health and Gender}

There is substantially strong evidence to justify significant contribution of gender-based differences to the higher prevalence of depression and anxiety disorders in girls and women compared to boys and men (WHO, 2002). Girls and women suffer more from sexual violence, with strong association between childhood sexual abuse and multiple mental health problems later in life (WHO, 2002). These differences can be attributed to both gender disparities and social inequalities (Yu, 2018). The link between women's disadvantaged status and their mental health obliges mental health professionals to understand the contribution of social context to the origin and persistence of their patient's problems (Carmen et al., 1984).

Context-specific gender-sensitive mental health policies and programs in Africa would be more beneficial through consultations with the women and girls who should not simply be considered as beneficiaries but also as the agents of change 
(WHO, 2002). Additional measures to prevent mental health problems among African women and girls should include empowerment while taking gender into account in setting mental health priorities and needs (WHO, 2002). This aligns with the WHO sustainable development goal five, which seeks to achieve gender equality and empower women and girls (WHO, 2019).

\section{Mental Health Policy and Mental Health Outcomes}

The World Health Organisation defines a mental health policy as, "an organized set of values, principles and objectives for improving mental health and reducing the burden of mental disorders in a population. It determines a vision for the future and establishes a model for action.” It has five cardinal functions in a mental health system which includes: providing a general roadmap for mental health, prioritising mental health, coordinated development of mental health services, identifying key stakeholders and allowing stakeholders to reach an agreement in the provision of services. Effective mental health policy development can begin at the top or from the grass roots (WHO, 2005b), but needs to be consultative and inclusive. A policy originating at the top without involvement of stakeholders is likely to face challenges during the implementation phase. Ministries of Health should therefore focus on consultations and negotiations at each stage of the policy development (WHO, 2005b). This provides the opportunity for all stakeholders to evaluate relevant values and principles, and consider reasonable options that could help address the mental health challenges within their context.

Despite the complications of policy development, implementation and evaluation, evidence-based mental health policy development, pulling together the experiences of patients, lawyers, traditional leaders, traditional healers, nongovernmental organisations, clinicians and researchers has a higher probability to succeed due to its inclusive and participatory approach, especially in a low resource setting like Africa.

\section{Research in Mental Health}

Research on mental health, consumers of services, and effective interventions in low-middle income countries is crucial in scaling up mental health services considering its role in identifying needs for a particular setting, and proposing culturally appropriate and cost-effective interventions. Furthermore, investigation of the implementation of evidence based intervention and establishment of barriers that hinder the scale up of efficacious interventions (modern psychotropic medications and psychotherapeutic interventions like cognitive behavioural therapy) in low-middle income settings adapted for local contexts is needed. However, the capacity to conduct research in low-middle income countries is extremely limited (Thornicroft et al., 2012). Obstacles include limited number of specialists, funding, poor clinical practice and institution-based administrative obstacles. Furthermore, programs like Psychiatry attract very few trainees in the African setting. For instance, Zambia, with a population of over 17 million, offers postgraduate training in psychiatry for medical practitioners but the program attracts less than five postgraduate students per intake. Majority divert to internal medicine, obstetrics and gynaecology, general surgery, orthopaedic surgery, paediatrics, infectious disease and public health on the premise that mental health is not prioritised in Low income countries. The situation is not different in Cameroon, with stigma associated with specialisation in mental health.

Considering the limited resources, it is important for lowmiddle income countries to adopt a multi-disciplinary approach to mental health research. Collaboration between researchers, doctors, administrators, government officials, non-governmental organisations and the community can transform the research landscape in low-middle income countries (Wei, 2008). Skills that enable researchers to effectively engage community stakeholders, journalists, decision-makers, and policy making organizations at all stages of research activities are crucial in creating required impact (Collins et al., 2013).

\section{Mental Health Financing}

Mental disorders contribute a significant and growing proportion to the global burden of disease and yet remain very poorly financed, globally and specifically in Africa (Dixon et al., 2006). This contributes to lack of scale up of potentially successful evidence-based interventions that could help maintain or reintegrate mentally ill persons into society, and may be cost-effective compared to the counterfactual (Chisholm et al., 2004). Considering the adverse economic consequences of mental disorders on families in low-middle income countries, there is need to offer financial protection and service coverage for afflicted families. Strategies include implementing National Health Insurance Scheme; shifting to Results Based Financing; decentralizing mental health services that can be provided at community level; and sustained advocacy backed by research evidence (Ssebunnya et al., 2018). National Health Insurance Scheme is the most viable provided there is scale up to intervention at community level facilities (Ssebunnya et al., 2018).

Zambia and Cameroon offer National Health Insurance Scheme for all health care services at government facilities. A study to evaluate the impact of National Health Insurance Scheme on access to mental health services for individuals with mental illness would be worth conducting in the two countries.

\section{CONCLUSION}

The Mental Health Care in a Public Health Context Australia Awards short course took a partnerships approach between professional resources in a high-income country and promising health-related institutions in low-middle income countries to conduct skills transfer. Building capacity of health workers to address the global mental health workforce shortage is crucial amidst increasing prevalence of mental illness and mental disorder. The course included site visits to innovative strategies for mental health care within the community and hospital setting, like stepping stone and the trauma centre, which if culturally adopted to the participants' local setting has the potential to transform mental health care in Africa. The interactive seminars and lectures led to a 
number of lessons for mental health care strengthening in Africa, including task-sharing as an innovative method of mental health delivery, as well as planning mental health activities with the various key stakeholders as a way of maximising success of interventions.

Countries where mental health has not been given due attention need to begin with a policy that recognises mental health as a core component of physical health. Such policy will facilitate programme planning, implementation, monitoring and evaluation. This can only be possible if governments show political will and provide funding for mental health care. Leadership in low income countries also need to consider poverty reduction as an ambitious strategy to address mental health problems. Collaboration in mental health research and training scholarships constitutes good measures to build capacity and create awareness of the importance of mental health in countries where it is still unrecognised.

There is need for specialised hospitals for mental health care in low income countries to generate innovative strategies that address problems of stigma and to consider integration of mental health services to primary care facilities, with plans of deinstitutionalising mental health service delivery.

\section{RECOMMENDATIONS}

\section{Low to Middle Income Countries}

We recommend that low-middle income countries in Africa may:

- Engage all key stakeholders including consumers when designing programs and policies for mental health services.

- Adopt a task-shifting approach to address the scarce human resource for mental health services.

- Adopt a biopsychosocial-cultural model to explain the interaction between mental health and chronic illness, and strengthening the integration of mental health into general health care.

- Generate innovative strategies to address stigma and improve mental health seeking behaviour among affected people.

- Address both fidelity and fit when adapting psychological tools to local cultural contexts.

- Incorporate awareness of gender into mental health research and care and promote gender equality and social inclusion in the African context.

- Collaborate in research in mental health across institutions in LMICs to better reveal the disease burden and propose context-specific Solutions.

High Income Countries

- We recommend that the Australian Government continues to support the Mental Health Care Program in a public health context through its Department of Foreign Affairs and Trade (DFAT).

- We further recommend that other high resource countries emulate the Australian Government and offer training opportunities to support mental health human resource development in an African context.

\section{REFERENCES}

Bährer-Kohler, S. and Carod-Artal, F. J. (Eds.). (2017). Global Mental Health. Springer International Publishing. https://doi.org/10.1007/978-3-319-59123-0

Bharadwaj, P., Pai, M. M. and Suziedelyte, A. (2017). Mental health stigma. Economics Letters, 159, 57-60. https://doi.org/10.1016/j.econlet.2017.06.028

Bolton, D. and Gillett, G. (2019). The Biopsychosocial Model of Health and Disease: New Philosophical and Scientific Developments. Springer International Publishing. https://doi.org/10.1007/978-3-030-11899-0

CalMHSA. (2010). California Mental Health Services Authority. Statewide prevention and early intervention implementation work plan. Available at: http://calmhsa.org/wp-content/ uploads/2012/01/CalMHSA-Implementation-Work-PlanFINAL-11-18-10-POSTED.pdf (Accessed 4 April 2020).

Carmen, E. (Hilberman), Russo, N. F. and Miller, J. B. (1984). Inequality and Women's Mental Health. In P. P. Rieker \& E. (Hilberman) Carmen (Eds.), The Gender Gap in Psychotherapy: Social Realities and Psychological Processes (pp. 17-39). Springer US. https://doi.org/10.1007/978-14684-4754-5_3

Castro, F. G., Barrera, Jr., M. and Martinez, Jr., C. R. (2004). The Cultural Adaptation of Prevention Interventions: Resolving Tensions Between Fidelity and Fit. Prevention Science, 5(1), 41-45. https://doi.org/10.1023/B:PREV. 0000013980.12412.cd

Chibanda, D. (2011). Problem-solving therapy for depression and common mental disorders in Zimbabwe: Piloting a task-shifting primary mental health care intervention in a population with a high prevalence of people living with HIV | BMC Public Health. https://bmcpublichealth. biomedcentral.com/articles/10.1186/1471-2458-11-828

Chibanda, D., Weiss, H. A., Verhey, R., Simms, V., Munjoma, R., Rusakaniko, S., Chingono, A., Munetsi, E., Bere, T., Manda, E., Abas, M. and Araya, R. (2016). Effect of a Primary Care-Based Psychological Intervention on Symptoms of Common Mental Disorders in Zimbabwe: A Randomized Clinical Trial. JAMA, 316(24), 2618. https://doi.org/10.1001/jama.2016.19102

Chisholm, D., Sanderson, K., Ayuso-Mateos, J. L. and Saxena, S. (2004). Reducing the global burden of depression: Population-level analysis of intervention costeffectiveness in 14 world regions. The British Journal of Psychiatry: The Journal of Mental Science, 184, 393-403. https://doi.org/10.1192/bjp.184.5.393

Clark, W., Welch, S. N., Berry, S. H., Collentine, A. M., Collins, R., Lebron, D. and Shearer, A. L. (2013). California's Historic Effort to Reduce the Stigma of Mental Illness: The Mental Health Services Act. American Journal of Public Health, 103(5), 786-794. https://doi.org/10.2105/AJPH. 2013.301225 
Collins, P. Y., Tomlinson, M., Kakuma, R., Awuba, J. and Minas, H. (2013). Research Priorities, Capacity, and Networks in Global Mental Health. In V. Patel, H. Minas, A. Cohen and M. Prince (Eds.), Global Mental Health (pp. 425-449). Oxford University Press. https://doi.org/10.1093/med/ 9780199920181.003.0019

Directory of Services and Resources for Survivors of Torture. (2003). U.S. Department of Health and Human Services, Substance Abuse and Mental Health Services Administration, Center for Mental Health Services.

Dixon, A., McDaid, D., Knapp, M. and Curran, C. (2006). Financing mental health services in low- and middleincome countries. Health Policy and Planning; Oxford, 21(3), 171-182. https://doi.org.ezp01.library.qut.edu.au/10.1093/ heapol/czl004

Engel, G. L. (1977). The need for a new medical model: A challenge for biomedicine. Science, 196(4286), 129-136. https://doi.org/10.1126/science.847460

Freeman, M. (2016). Global mental health in low and middle income, especially African countries. Epidemiology and Psychiatric Sciences, 25(6), 503-505. https://doi.org/ 10.1017/S2045796016000482

Fricchione, G. L., Borba, C. P. C., Alem, A., Shibre, T., Carney, J. R. and Henderson, D. C. (n.d.). Capacity Building in Global Mental Health: Professional Training. Harvard Review of Psychiatry, 20(1), 47-57. https://doi.org/10.3109/10673229.2012.655211

Gagliese, L., Gauthier, L. R., Narain, N. and Freedman, T. (2018). Pain, aging and dementia: Towards a biopsychosocial model. Progress in NeuroPsychopharmacology and Biological Psychiatry, 87, 207-215. https://doi.org/10.1016/j.pnpbp.2017.09.022

Goffman, E. (1963). Stigma: Notes on the management of spoiled identity. Penguin. Available at: https://www.freelists.org/ archives/sig-dsu/11-2012/pdfKhTzvDIi8n.pdf

Hailemariam, M., Fekadu, A., Selamu, M., Alem, A., Medhin, G., Giorgis, T. W., DeSilva, M. and Breuer, E. (2015). Developing a mental health care plan in a low resource setting: The theory of change approach. BMC Health Services Research, 15. https://doi.org/10.1186/s12913-0151097-4

Health on the mind. (2018, February 14). Who or WHO's Definition of Health? Health on the Mind. https://healthonthemind.wordpress.com/2018/02/14/who -or-whos-definition-of-health/

Hoeft, T. J., Fortney, J. C., Patel, V. and Unützer, J. (2018). Task-Sharing Approaches to Improve Mental Health Care in Rural and Other Low-Resource Settings: A Systematic Review. The Journal of Rural Health: Official Journal of the American Rural Health Association and the National Rural Health Care Association, 34(1), 48-62. https://doi.org/ 10.1111/jrh.12229

Iliescu, D. (2017, October). Adapting Tests in Linguistic and Cultural Situations. Cambridge Core. https://doi.org/ 10.1017/9781316273203
Joshi, R., Alim, M., Kengne, A. P., Jan, S., Maulik, P. K., Peiris, D. and Patel, A. A. (2014). Task Shifting for NonCommunicable Disease Management in Low and Middle Income Countries - A Systematic Review. PLoS ONE, 9(8). https://doi.org/10.1371/journal.pone.0103754

Pilgrim, D. (2015). The Biopsychosocial Model in Health Research: Its Strengths and Limitations for Critical Realists. Journal of Critical Realism, 14(2), 164-180. https://doi.org/10.1179/1572513814Y.0000000007

QPAST. (2014). Counselling. Qpastt.Org.Au. Available at: https://qpastt.org.au/what-we-do/counselling/

QUT, Q. U. of T. (2019). Mental health professionals from nine African nations at QUT for a customised course [News]. QUT. Available at: https://www.qut.edu.au/news?id= 149849

Rodgers, R. F., Paxton, S. J. and McLean, S. A. (2014). A Biopsychosocial Model of Body Image Concerns and Disordered Eating in Early Adolescent Girls. Journal of Youth and Adolescence, 43(5), 814-823. https://doi.org/10.1007/s10964-013-0013-7

Sankoh, O., Sevalie, S. and Weston, M. (2018). Mental health in Africa. The Lancet Global Health, 6(9), e954-e955. https://doi.org/10.1016/S2214-109X(18)30303-6

Soghoyan, A. and Gasparyan, K. (2017). Mental Health and Stigma. In S. Bährer-Kohler \& F. J. Carod-Artal (Eds.), Global Mental Health: Prevention and Promotion (pp. 61-69). Springer International Publishing. https://doi.org/10.1007/ 978-3-319-59123-0_6

Ssebunnya, J., Kangere, S., Mugisha, J., Docrat, S., Chisholm, D., Lund, C. and Kigozi, F. (2018). Potential strategies for sustainably financing mental health care in Uganda. International Journal of Mental Health Systems, 12(1), 74. https://doi.org/10.1186/s13033-018-0252-9

Staples, L. and Stein, R. (2008). The clubhouse model: Mental health consumer-provider partnerships for recovery. In Advances in Medical Sociology (Vol. 10, pp. 177-196). Emerald (MCB UP). https://doi.org/10.1016/S10576290(08)10009-2

Suls, J. and Rothman, A. (2004). Evolution of the Biopsychosocial Model: Prospects and Challenges for Health Psychology. Health Psychology, 23(2), 119-125. https://doi.org/10.1037/0278-6133.23.2.119

Susskind, J. (2013). Mental Health Services Act (MHSA) Community Program Planning Process FY 2019/20. Available at: https://www.edcgov.us:443/Government/MentalHealth /mhsacpppfy1920

Thornicroft, G., Cooper, S., Van Bortel, T., Kakuma, R. and Lund, C. (2012). Capacity Building in Global Mental Health Research. [Miscellaneous Article]. Harvard Review of Psychiatry, 20(1), 13-24. https://doi.org/10.3109/10673229. 2012.649117

VFST. (2016). Foundation House: Supporting Refugees to Rebuild their Lives. Foundation House. Available at: https://foundationhouse.org.au/ 
Wade, D. T. and Halligan, P. W. (2004). Do biomedical models of illness make for good healthcare systems? BMJ: British Medical Journal, 329(7479), 1398-1401. https://doi.org/ 10.1136/bmj.329.7479.1398

Wei, F. (2008). Research capacity for mental health in low- and middle-income countries: Results of a mapping project. Bulletin of the World Health Organization, 86(11), 908-908. https://doi.org/10.2471/BLT.08.053249

WHO. (2001). WHO | The world health report 2001 - Mental Health: New Understanding, New Hope. WHO. Available at: https://www.who.int/whr/2001/en/

WHO. (2002). WHO | Gender and mental health. WHO. Available at: https://www.who.int/gender-equityrights/knowledge/a85573/en/

WHO (Ed.). (2005a). Human resources and training in mental health. World Health Organization. Available at: https://www.who.int/mental_health/policy/services/11_hu man\%20resource_training_WEB_07.pdf?ua=1
WHO. (2005b). WHO | The WHO mental health policy and service guidance package. WHO. Available at: http://www. who.int/mental_health/policy/essentialpackage1/en/

WHO. (2017). WHO | Mental Health ATLAS 2017. WHO. Available at: http://www.who.int/mental_health/evidence/ atlas/mental_health_atlas_2017/en/

WHO. (2019). Stronger collaboration, better health. WHO. Available at: https://www.who.int/publications-detail/ stronger-collaboration-better-health-global-action-planfor-healthy-lives-and-well-being-for-all

Wikipedia. (2020). Sustainable Development Goals. Wikipedia. Available at: https://en.wikipedia.org/w/index.php?title= Sustainable_Development_Goals \&oldid $=940295377$

Youssef, J. and Deane, F. P. (2006). Factors influencing mentalhealth help-seeking in Arabic-speaking communities in Sydney, Australia. Mental Health, Religion \& Culture, 9(1), 43-66. https://doi.org/10.1080/13674670512331335686

$\mathrm{Yu}, \mathrm{S}$. (2018). Uncovering the hidden impacts of inequality on mental health: A global study. Translational Psychiatry, 8. https://doi.org/10.1038/s41398-018-0148-0 